\title{
Deciphering lead and cadmium stripping peaks for porous antimony deposited electrodes
}

\author{
Aqeel Ahmad TAimoor* \\ Department of Chemical and Materials Engineering, Faculty of Engineering, King AbdulAziz University, \\ Jeddah, Saudi Arabia
}

\begin{abstract}
Cadmium and lead are generally taken as model heavy metal ions in water to scale the detection limit of various electrode sensors, using electrochemical sensing techniques. These ions interact with the electrochemically deposited antimony electrodes depending on the diffusion limitations. The phenomenon acts differently for the in-situ and ex-situ deposition as well as for porous and non-porous electrodes. A method has been adopted in this study to discourage the stripping and deposition of the working ions (antimony) to understand the principle of heavy metal ion detection. X-ray photoelectron spectroscopy (XPS) technique was used to establish the interaction between the working and dissolved ions. In addition to the distinct peaks for each analyte, researchers also observed a shoulder peak. A possible reason for the presence of this peak was provided. Different electrochemical tests were performed to ascertain the theory on the basis of the experimental observations.
\end{abstract}

Keywords: anodic stripping voltammetry; activated carbon; sensor electrodes

(C) Wroclaw University of Technology.

\section{Introduction}

Thin film electrodes for heavy metal ions detection in water by anodic stripping are widely used because of their simple fabrication, cost effectiveness, robustness, flexibility and reliability $[1,2]$. In these electrodes, active metal is fashioned over the surface of a conductive support. Doped metal enhances the current to voltage signal for the analytes and can detect heavy metals present in water up to ppb levels. Mercury [3-8], bismuth [9-11], gold [12-14], platinum [15] and tin [16] are examples of active metals reported in literature. Mercury and bismuth are usually used because of their superior properties. Recent studies focus on antimony as an active metal to meet mercury and bismuth free environment. Antimony has also shown a wide operational window, favorable negative hydrogen overpotential and low self-stripping [17].

Both in-situ and ex-situ antimony deposition over the substrate surface has been presented in literature. Although in-situ prepared antimony electrode has superior properties for the detection of $\mathrm{Cd}$

\footnotetext{
${ }^{*}$ E-mail: ataimoor@kau.edu.sa
}

and $\mathrm{Pb}$ ions [18] but it adds toxic antimony into the test solution and is thus discouraged [19]. Ex-situ preparation of the electrode usually requires electroplating in an antimony mother solution. As the amount of current per unit area controls the layer thickness in electroplating, therefore most of the studies (in-situ and ex-situ) prefer electrodeposition for electrode preparation. However, this technique does not chemically bind the active metal to the surface and once the anodic potential is applied, active metal is stripped along with the analytes. The electrode must then be cleaned and re-deposited (with exact parameters) between two consecutive tests to reproduce the results.

Generally, the impregnation of catalytically active metals on the support surfaces is used to produce catalysts. Expertise in this method may yield high dispersion $(>80 \%)$ of active ingredients to produce catalytically active surfaces. Impregnation method has been employed in this study to enhance the electrode surface properties, besides reduction of antimony stripping so that the electrode could be used for multiple times with reasonable accuracy and without the need of any interim regeneration. Antimony has higher melting temperature 
compared to bismuth and mercury and is thus more suitable to avoid excessive vapor loss during electrode preparation (as impregnation requires subsequent high temperature calcination and reduction).

Thin film electrodes essentially work according to the surface phenomena of charge transfer and adsorption. Therefore large surface area can be translated into greater sensitivity (or signal to noise ratio). The sensitivity of porous antimony electrodes for the detection of heavy metals ions is reported to be three times higher than that of the non-porous ones [20]. Our previous work [21] has shown that antimony deposited on porous activated carbon gives better detection limits, mainly because of the higher active surface area. This research provides further insight of the process and theoretical reflections are discussed to elucidate the effect of impregnation.

Although many studies, like the referenced above, on the use of antimony electrodes prepared by different methods have been reported, but the mechanism and kinetics are not well understood. The individual peak areas are different for different ratios of analytes concentrations. Furthermore, a shoulder peak has also been observed in earlier studies. To explain these behaviors, it is important to understand the surface processes going on during the electrode application. True calibration/precision of detection of the electrodes has to be done according to the well-recognized mechanism.

\section{Experimental}

\subsection{Antimony impregnation}

The preparation process of antimony impregnated activated carbon is presented graphically in Fig. 1. All chemicals used were of laboratory grade purity. Activated carbon from Norrit was regenerated at $220{ }^{\circ} \mathrm{C}$ with a ramp of $25{ }^{\circ} \mathrm{C} / \mathrm{min}$ for $2 \mathrm{~h}$, in ECF-12/4A furnace provided by Lanten, to remove any impurity present on the surface. The surface area was determined by BET equipment and was approximately equal to $550 \mathrm{~m}^{2} / \mathrm{g}$ to $700 \mathrm{~m}^{2} / \mathrm{g}$. Antimony trichloride $\left(\mathrm{SbCl}_{3}\right)$ from Sigma Aldrich was taken as the precursor for the subsequent impregnation of antimony metal over an activated carbon support. $37 \% \mathrm{HCl}$ from the Scharlau was taken as the supporting solution for the impregnation. Vacuum impregnation was carried out at $90^{\circ} \mathrm{C}$ and $60 \mathrm{kPa}$ pressure for $4.5 \mathrm{~h}$ in XA-43 rotary vacuum evaporator provided by KeiSon (BIBBY Scientific). Drying of samples was done at $120^{\circ} \mathrm{C}$ with a ramp of $12{ }^{\circ} \mathrm{C} / \mathrm{min}$ for $2 \mathrm{~h}$ in JSON-150 oven provided by JSR to remove the water and other volatile impurities from the prepared samples. Subsequent calcination was performed under nitrogen atmosphere at $300{ }^{\circ} \mathrm{C}$ with a ramp of $10{ }^{\circ} \mathrm{C} / \mathrm{min}$ for $2 \mathrm{~h}$ in CTF-12/C5 muffle furnace provided by Carbolite to remove the impregnation impurities from the prepared samples.

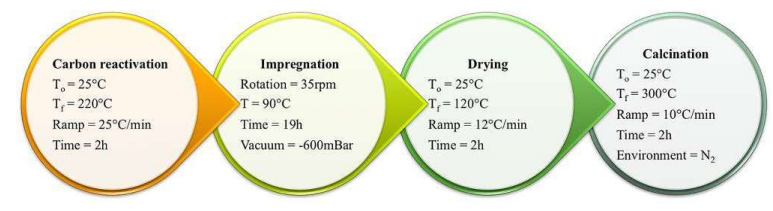

Fig. 1. Process flow chart for the preparation of antimony impregnated activated carbon electrode, $T_{o}$ and $T_{f}$ are the initial and final temperatures, respectively.

\subsection{Electrode preparation}

The impregnated activated carbon was then reduced under hydrogen at $550{ }^{\circ} \mathrm{C}$ and tested in electrochemical cells. Paraffin $\left(\mathrm{C}_{12}-\mathrm{C}_{14}\right)$ as a binder was used to hold the sample granules over a particularly developed copper-plastic piston-working electrode. Usually a layer of impregnated carbon paste contained $0.05 \mathrm{~g}$ activated carbon $(0.0025 \mathrm{~g}$ antimony) and $0.08 \mathrm{~g}$ paraffin.

\subsection{Temperature programmed reduction (TPR)}

Temperature programmed reduction (TPR) analysis was carried out in ChemBET PULSAR TPR/TPD equipment provided by Quantachrome. The sample tube was first purged by helium with temperature ramp of $4{ }^{\circ} \mathrm{C} / \mathrm{min}$ up to $150{ }^{\circ} \mathrm{C}$ for an hour. The sample was then cooled to $40{ }^{\circ} \mathrm{C}$. $5 \% \mathrm{H}_{2} / \mathrm{N}_{2}$ mixture in reduction environment. The temperature was then raised to $525^{\circ} \mathrm{C}$ with the ramp of $5{ }^{\circ} \mathrm{C} / \mathrm{min}$. 


\subsection{X-ray photoelectron spectroscopy} (XPS)

The XPS measurements were carried out on a SPECS (GmbH, Germany) photoelectron spectrometer operating at a base pressure of $4 \times 10^{-9} \mathrm{kPa}$. A non-monochromatic $\mathrm{MgK} \alpha$ $(1253.6 \mathrm{eV}) \mathrm{X}$-ray source was used to irradiate the sample surface with $13.5 \mathrm{kV}, 100 \mathrm{~W}$ X-ray power. The sample was positioned at a take-off angle of $90^{\circ}$ to the surface normal. XPS spectra were collected at room temperature utilizing a PHOIBOS 150 MCD-9 hemispherical energy analyzer operating in Fixed Analyzer Transmission (FAT) mode. The analyzer was set to the Medium Area (MA) lens mode with a rectangular entrance slit of $7 \times 20 \mathrm{~mm}^{2}$. The survey scans were obtained with the analyzer pass energy of $30 \mathrm{eV}$, while the high resolution-narrow scans of the elements were recorded at $20 \mathrm{eV}$, energy step of $25 \mathrm{meV}$ and dwell time of $100 \mathrm{msec}$. As the standard practice in XPS studies, the adventitious hydrocarbon-type carbon $\mathrm{C} 1 \mathrm{~s}$ line set to $284.8 \mathrm{eV}$ corresponding to $\mathrm{C}-\mathrm{C}$ bond has been used for all XPS spectra as binding energy reference for charge correction. All XPS spectra were processed and analyzed using the CasaXPS software version 2.3.16Dev52.

\subsection{Voltammetry}

Carbon electrode was used as a counter electrode with $\mathrm{Ag} / \mathrm{AgCl}$ reference electrode. Analyte solution consisted of $100 \mu \mathrm{g} / \mathrm{L} \mathrm{Pb}^{+2}$ and $\mathrm{Cd}^{+2}$ (precursors: lead nitrate and cadmium chloride monohydrate from Loba Chemie), supported in a $0.01 \mathrm{M}$ $\mathrm{HCl}$ electrolyte solution $(\mathrm{pH}=2)$. Three-electrode system was used to carry out electrochemical tests on PG STAT-101 potentiostat provided by AUTOLAB and powered by NOVA software. Deposition potential of $-0.1 \mathrm{~V}$ was given to the solution with a deposition time of 10 minutes, unless stated otherwise. Stepping potential was set to $4 \mathrm{mV}$, frequency was set to $30 \mathrm{~Hz}$ and amplitude to $50 \mathrm{mV}$.

\section{Results}

Reduction temperature for Antimony Impregnated Activated Carbon (AIAC) was determined by
TPR analysis (Fig. 2). The sample starts to consume hydrogen at $80{ }^{\circ} \mathrm{C}$ with a constant rise up to $500{ }^{\circ} \mathrm{C}$. This is attributed to the methane formation (methanation). The reaction is favored by thermodynamics at low temperatures but the kinetics is slow [22]. Steady hydrogen consumption increases as the kinetics increases with temperature. Methane formation by hydrogen and carbon is an exothermic reaction, therefore high temperature results in significant backward reaction and thus overall decrease in hydrogen consumption above $540{ }^{\circ} \mathrm{C}$. The peaks observed at $380^{\circ} \mathrm{C}$ are caused by antimony reduction. The sample reduction is therefore conducted at $550{ }^{\circ} \mathrm{C}$ under hydrogen to ensure complete antimony surface reduction and to avoid any sample loss because of methane formation. Temperatures higher than $550{ }^{\circ} \mathrm{C}$ are avoided to prevent any vapor loss of antimony [23].

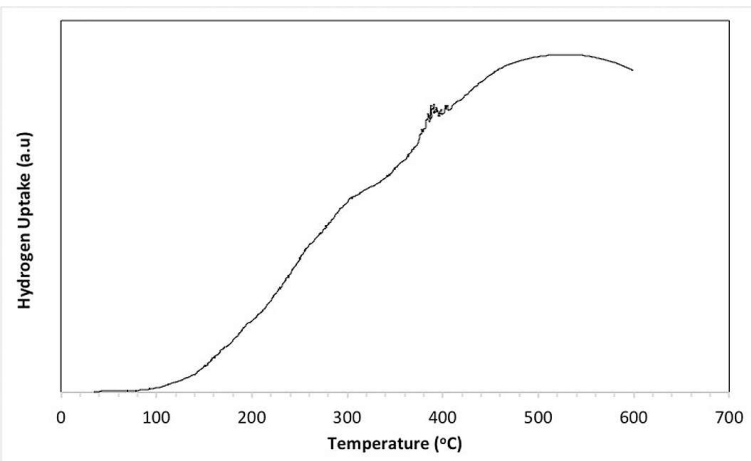

Fig. 2. TPR analysis of antimony impregnated activated carbon.

XPS analyses both for the antimony impregnated activated carbon (AIAC) and bare activated carbon samples are shown in Fig. 3. Only carbon binding energy $(\mathrm{BE})=284.6 \mathrm{eV}[24]$ and oxygen $\mathrm{BE}=533.6 \mathrm{eV}[25]$ peaks are present for activated carbon. However, chlorine peak $(\mathrm{BE}=200.2 \mathrm{eV}[26])$ as well as carbon and oxygen are observed on the surface of the AIAC. This chlorine is available as the antimony impregnation is done in $\mathrm{SbCl}_{3}$ dissolved in $0.1 \mathrm{M} \mathrm{HCl}$. The oxygen peak shifts from $532.6 \mathrm{eV}$ to $533.6 \mathrm{eV}$ for AIAC because various oxygen and antimony compounds overlap in their bond energies [27]. Surface species in this region thus requires deconvolution of the peaks as shown in Fig. 4. Two distinct 
peaks for metallic and oxidized antimony are separated by $9.3 \pm 0.15 \mathrm{eV}$ [28]. The oxidized antimony peak is either due to antimony oxide or antimony complex of carboxylic groups [29]. The complex of such groups with chlorine has also been observed at $200.53 \mathrm{eV}$ in chlorine deconvoluted plot [30]. The antimony peaks are not present in the deconvoluted plot of oxygen for bare activated carbon. According to Fig. 5 (the deconvoluted oxygen peaks for calcined, reduced and deposited AIAC), higher intensities for reduced antimony (metallic) are found on the surface of AIAC after reduction compared to the calcined sample. However, negligible peak intensity of oxidized antimony and no metallic antimony is found after depositing cadmium and lead analytes for $10 \mathrm{~min}$ over the sample surface. After lead and cadmium deposition, total amount of surface antimony decreased from $2 \%$ to $0.03 \%$ as per the peaks quantification.

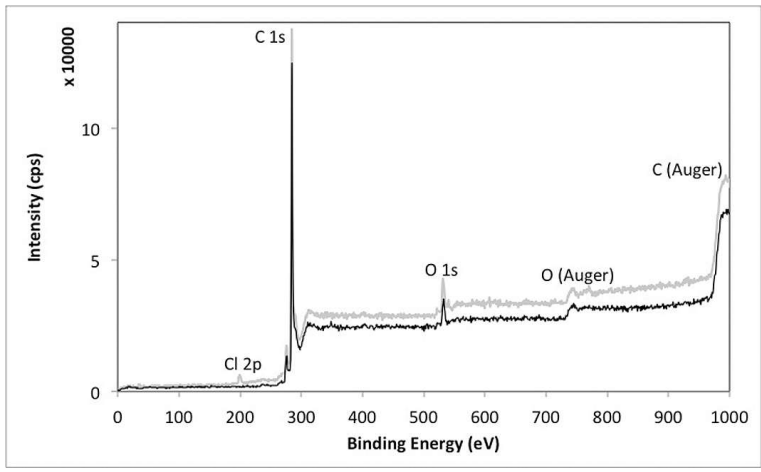

Fig. 3. XPS survey peaks, dark line - activated carbon, shaded line - AIAC.

Cyclic voltametry results for activated carbon and AIAC are presented in Fig. 6. The scan rate was $4 \mathrm{mV} / \mathrm{s}$. Stripping analysis for detection of lead and cadmium was performed at the same scan rate. The voltage ramp starts from the cathodic region $(-1 \mathrm{~V})$ and increases up to the final voltage $(1 \mathrm{~V})$ before reversal. The distance between the forward and backward scans (hysteresis) is less for AIAC than for bare activated carbon. This indicates that double layer diffusion resistance in the activated carbon is high compared to the AIAC [31]. The blockage of the small pores of activated carbon by impregnated antimony in AIAC results in lower internal diffusion resistance.

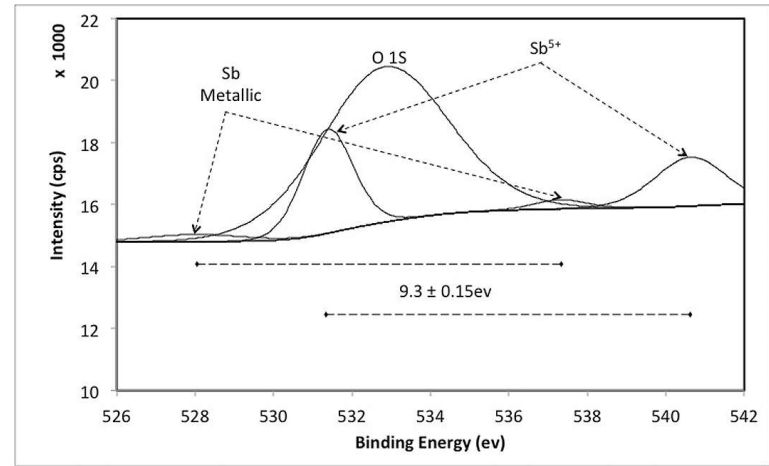

Fig. 4. Deconvoluted XPS plot for the oxygen and antimony peaks for AIAC.

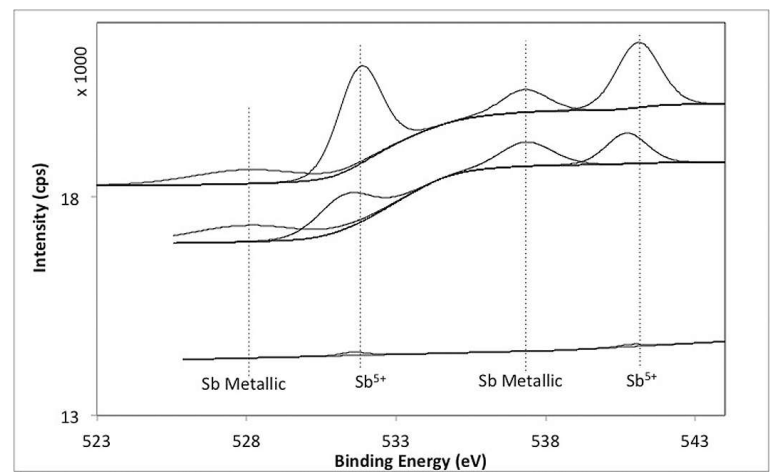

Fig. 5. Deconvoluted XPS peaks for antimony, top - after calcination, middle - after reduction, bottom - after deposition of $\mathrm{Cd}$ and $\mathrm{Pb}$ for $10 \mathrm{~min}$.

Furthermore, no antimony reduction (reduction potential $\cong 0 \mathrm{~V}$ vs. $\mathrm{Ag} / \mathrm{AgCl}$ ) peak occurs. The curves have been replotted during the same run i.e. voltage was reversed three times showing no appreciable difference. This is in accordance to the XPS results and antimony at the surface of the activated carbon is bonded chemically (justification provided in discussion section). The results were also analyzed by $\Delta \mathrm{I}$ vs. $\mathrm{V}$ plot with no evidence of antimony stripping.

Fig. 7 provides the square wave anodic stripping results. The test was conducted in a solution of $100 \mathrm{ppb}$ of lead and cadmium. There are three peaks for bare activated carbon. The support offers some detection capabilities as mentioned in earlier studies [32]. The ions of lead and cadmium enter in the micro pores during the deposition step and are not able to escape after reduction because 


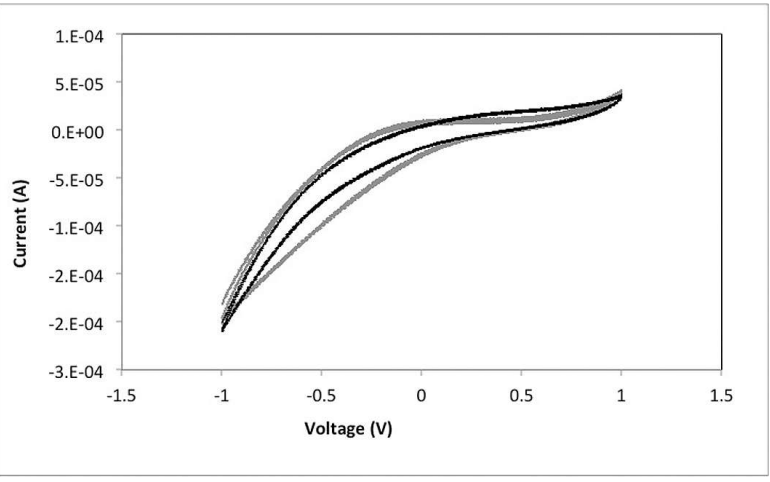

Fig. 6. Cyclic voltammetry plot for activated carbon (shaded line ) and AIAC (dark line). Voltage step size $=4 \mathrm{mV} / \mathrm{s}$.

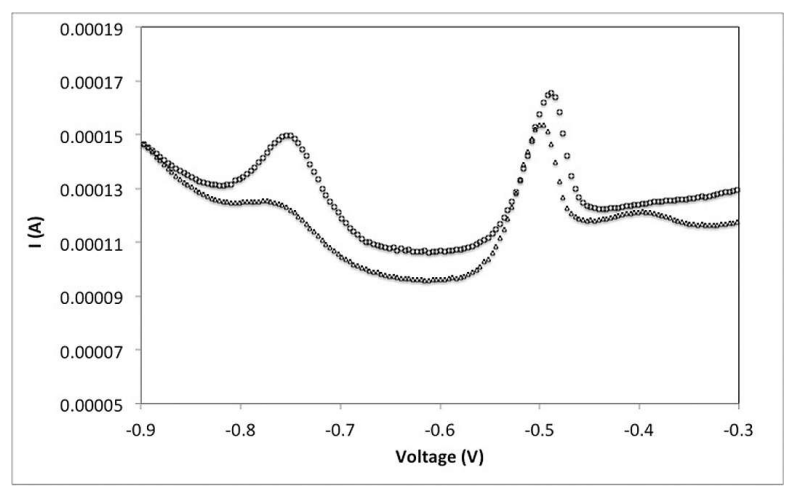

Fig. 7. Square wave stripping voltammetry results for

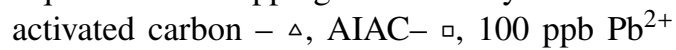
and $\mathrm{Cd}^{2+}$ solution: $0.01 \mathrm{M} \mathrm{HCl}(\mathrm{pH} 2)$, deposition at $-0.1 \mathrm{~V}$ for $10 \mathrm{~min}$ at a frequency of $30 \mathrm{~Hz}$, amplitude of $50 \mathrm{mV}$ and a potential step of $4 \mathrm{mV}$.

of the size expansion (due to oxidation), gravitational or geometrical reasons. These trapped metals in the pores matrix, however can be oxidized using the anodic current and thus show the stripping peak for the relative metal. The first $(\approx-0.78 \mathrm{~V})$ and second $(\approx-0.5 \mathrm{~V})$ peaks are of cadmium and lead respectively. The third smaller peak (shoulder peak) $(\approx-0.4 \mathrm{~V})$ for activated carbon is attributed to some complex formation according to Urbanová et al. [20]. For AIAC, the peak area is much larger showing strong affinity of the heavy metals towards antimony but no antimony is stripped off (around $0 \mathrm{~V}$ no peak is observed) from the surface of the AIAC.
In Fig. 8, all peaks areas increase with successive testing of the same AIAC electrode sample in $100 \mathrm{ppb}$ of lead and cadmium solution without any intermittent treatment. A 6 min deposition potential was maintained for each run. During this experiment there was no pause between the reduction step of previous and the deposition step of the subsequent test run. As an overall ions concentration in the double layer increases with each run, thus every next experiment shows higher stripping current than the former one. However, the third peak (shoulder peak of lead) starts to appear after $25 \mathrm{~min}$ and is attributed to the increased concentration of the analytes in electrode vicinity. The observed shoulder peak is not caused by oxygen reaction as it was also reported in the studies without oxygen in the solution [20].

Fig. 9 shows the effect of the antimony content present in the electrode, in $100 \mathrm{ppb}$ solution of each lead and cadmium, on the shoulder peak. Deposition voltage has been maintained for $10 \mathrm{~min}$. A linear trend is observed between the amount of exposed antimony and the area of the shoulder peaks $(\approx-0.4 \mathrm{~V})$. More antimony results in decreased shoulder peak area and vice versa. It may be concluded that antimony hinders the appearance of this peak. The shoulder peak was absent for in-situ prepared electrodes studied earlier as antimony amount was higher for the in-situ prepared electrodes, thus obstructing the peak. Furthermore, this peak was also absent when the deposition time was shorter.

Using the dilution method, separate solutions of lead and cadmium were prepared with the same concentration of both the analytes ranging from $50 \mathrm{ppb}$ to $100 \mathrm{ppb}$. Voltammetry results are provided in Fig. 10. The shoulder peak at low concentration does not appear. However, with an increase in the analytes concentration the shoulder peak starts to appear. An exponential calibration curve is then observed. The electrode can be calibrated linearly, up to the appearance of the shoulder peak (as it is done for in-situ prepared electrodes with no peak at $-0.4 \mathrm{~V}$ ). However, as this shoulder peak emerges, the trend for both lead and cadmium changes from linear to the exponential one. 


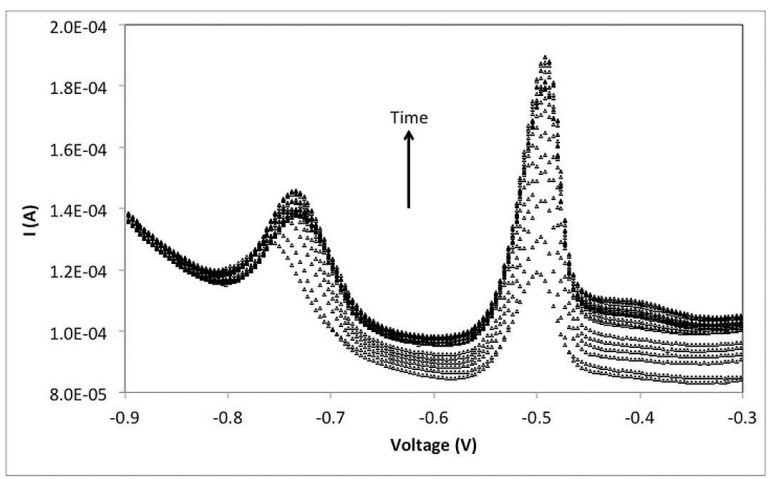

(a)

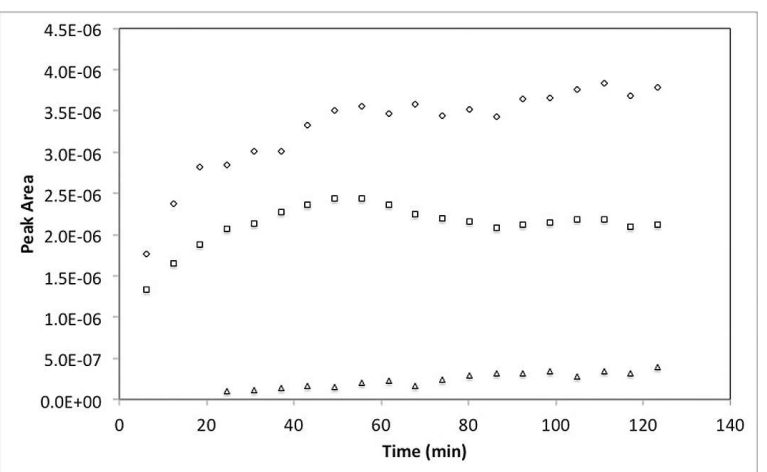

(b)

Fig. 8. Successive deposition and anodic stripping of AIAC, (a) actual peaks, (b) peak area $(\diamond-$ lead, - - cadmium and $\Delta-$ shoulder peak); Solution: $0.01 \mathrm{M} \mathrm{HCl}(\mathrm{pH} 2)$, deposition at $-0.1 \mathrm{~V}$ for $10 \mathrm{~min}$ at a frequency of $30 \mathrm{~Hz}$, amplitude of $50 \mathrm{mV}$ and a potential step of $4 \mathrm{mV}$.

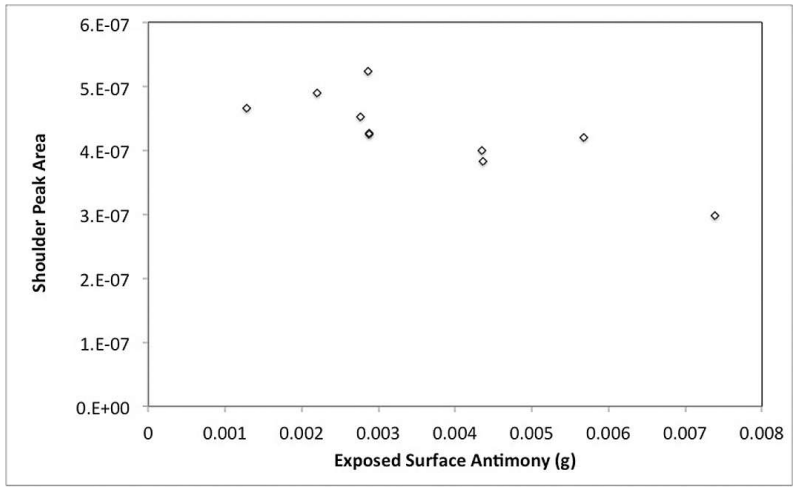

Fig. 9. Relation between the shoulder peak $(\approx-0.4 \mathrm{~V})$ area and the amount of antimony present in the sample. Solution: $0.01 \mathrm{M} \mathrm{HCl}(\mathrm{pH} 2)$, deposition at $-0.1 \mathrm{~V}$ for $10 \mathrm{~min}$ at a frequency of $30 \mathrm{~Hz}$, amplitude of $50 \mathrm{mV}$ and a potential step of $4 \mathrm{mV}$.

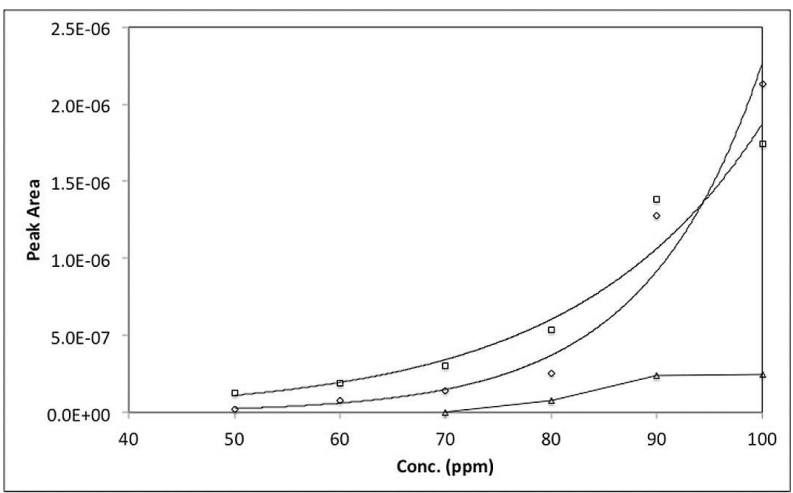

Fig. 10. Peak area at different analytes concentrations (simulated solutions), $\square-$ lead, $\diamond-$ cadmium, $\Delta-$ shoulder peak. Voltammograms are provided in the literature [21].

\section{Discussion}

The electrode is prepared by impregnation method, commonly employed in catalyst preparation. The catalyst performance is generally related to the surface defects. These surface defects are further enhanced by different active species to form temporary complexes over the surface and, hence, offer improved adsorption sites requiring less activation energy. These complexes are anticipated to form and alter the redox potential of antimony (both in voltammetry and striping analysis), therefore no peak for antimony is observed. XPS results have confirmed the presence of these complexes but the exact behavior of defects and active metal interactions are still under investigation.

Antimony provides the potential sites for heavy metals analyte to deposit on the electrode surface during deposition step. Antimony is known to form binary or intermetallic alloys with lead and cadmium [33]. However, this alloy formation is only possible when the antimony electrode is prepared in-situ. Composition of the resulting alloy is controlled by the relative diffusion of the ions during deposition. However, any ex-situ electrode preparation does not produce intermetallic alloy between antimony and the reducing ions because the temperature is too low to allow appreciable intermetallic diffusion. Furthermore, antimony in this study was chemically adsorbed on the surface and thus was not available for alloy formation (no stripping 
and subsequent deposition was observed for antimony during electrochemical testing). This suggests that layer stacking of the metallic atoms instead of antimony alloy, must be considered when reduction potential is applied.

Shoulder peak of lead was produced by antimony lead complex [19]. However, this peak existed, even when no antimony was present. On the other hand, antimony role in hindering its emergence cannot be excluded as observed in Fig. 7. Interestingly, this shoulder peak was reported by Svobodova-Tesarova et al. [32] for bare porous carbon paste electrodes and by Urbanová et al. [20] for macroporous antimony electrodes. The authors thus discouraged the use of bare electrodes but no reason for the shoulder peak emergence was given. As the kinetics is under pore diffusion control (evidence is provided in the next sub-section), thus theoretically cadmium must provide more efficient charge transportation during stripping than lead because of the smaller atomic/ionic size. It is interesting to note that the total charge produced during lead stripping is higher compared to cadmium stripping in any of the individual run. This is consistent with the observations found in the literature. The researchers explained this behavior on the basis of the difference in relative affinity of the two metals with antimony [11].

\subsection{Deposition step}

It is known that the deposition of ions over the active sites of electrodes is diffusion dependent and is controlled by the Cottrell's equation 1 [31]:

$$
i_{x}=\frac{n F A C_{x}^{o} \sqrt{D_{x}}}{\sqrt{\pi t}}
$$

where $\mathrm{n}$ is oxidation state, $\mathrm{F}$ is Faraday's constant, $A$ is surface area of the electrode, $C_{o}$ is the bulk concentration, $\mathrm{D}$ is diffusivity constant and $\mathrm{t}$ is the time.

If it is considered that all the atoms of any species $x$ oxidize in an event of stripping, then the relation simplifies to $i_{x}=\mathrm{kt}^{-1 / 2}$ (where $\mathrm{k}$ is a constant). Quantity of the stripped ions is determined by the integration of the signal peak. This is evident from the previous studies providing the relation between deposition time and current [34-37]. Their data can be modeled as per the equation, however the studies conducted by Hočevar et al. [38] provided a linear relationship (compared to parabolic). This anomaly may be attributed to the incomplete stripping of the ions. It has been thus established that surface electrochemical reaction kinetics is controlled by diffusion of the analyte ions and not by the adsorption or electrode charge transfer resistance. Stripping voltammetry is complex in nature; the peak area is the difference between the forward and backward scans for a very small voltage change. However, for these types of porous electrodes, kinetics is controlled by diffusion. So the current difference can be carefully considered proportional to the net difference between the quantities of diffusing ions in either direction. The shoulder peak indeed represents some kind of transportation across the boundary layer.

The ions of different analytes come in contact with the active surface and deposit themselves over the antimony or on the previously deposited analytes $(\mathrm{Cd} / \mathrm{Pb})$ ions. The charge transfer resistance causes that antimony on the electrode surface can capture the analyte more easily compared to the stacked atoms of antimony and analytes. So, the natural preference of deposition on antimony is there. However when no antimony is present (or surface antimony is exhausted), the layerwise stacking of the analytes cannot be ruled out.

\subsection{Stripping step}

When the electrode is under a stripping potential, oxidation depends on the stacking sequence of the metallic atoms. With the onset of certain oxidation potential, only that metal can be oxidized which is available on the surface (surface cadmium). Rest of the metal (cadmium) buried under the other deposited metal (lead), whose oxidation potential has yet to be achieved, cannot be oxidized because of the surface protection. However, once the oxidation potential of the protective metal (lead) is achieved all the metals (surface and metal under the surface) will oxidize instantly. The resultant peak (lead) is thus caused by both lead and cadmium which was not previously exposed (when 
the oxidation potential of cadmium was reached). So, the subsequent peak of lead + cadmium shows higher current than cadmium alone. The sensitivity difference in lead and cadmium for in-situ and exsitu electrodes as reported by Jovanovski et al. [39] may be caused by the same reason.

The shoulder peak of lead is caused by the oxidation of lower surface atomic layers. According to Fig. 8, the thickness of the resistance layer increases with successive stripping (i.e. more ions are accumulating in the double layer with time; ionic diffusion to the bulk solution from the double layer is rate limiting), so the charge transfer resistance increases with time. Successive layer atoms have to face higher resistance and thus longer time to oxidize. This results in the extended shoulder peak of lead. The larger the number of stacking layers, the higher the area of the shoulder peak. This is in accordance to the obtained results. When no antimony was present on the surface, bare activated carbon and the analyte ions stuck in the matrix pores. These pores also offered higher diffusion resistance compared to the outer surface and hence, the shoulder peak is observed compared to the AIAC. Furthermore, the increase in the area of this shoulder peak with higher amount of analytes can also be explained by similar arguments. Although relative interference of the ions was reported by various researchers [36], but in most of the previous studies electrodes were calibrated by using one type of ionic species at a time in the test solution. The obvious result was in the form of linear calibration. On the other hand, mechanistic approach is required when more than one type of analytes are present in the real sample solution.

\section{Conclusion}

- Ex-situ deposition of active metal for the detection of analytes ions in stripping voltammetry does not involve alloy formation because of low temperature.

- Antimony deposited by impregnation forms surface complexes and although it enhances the signal to noise ratio it is not stripped during the oxidation potential step.
- Peak area of analytes is proportional to the amount of antimony present on the surface.

- Lead peak area is larger compared to that of cadmium, because the representative peak comes from lead and the underneath deposited cadmium ions.

- Presence of shoulder peak in case of macroporous electrodes is caused by the analytes layer-stacking phenomenon.

- Layer stacking deposition further explains the non-linear calibration behavior.

\section{Acknowledgements}

This research was funded by the Deanship of Scientific Research (DSR), the King Abdulaziz University, Jeddah, under the Grant No. (135-298-D1435). The author, therefore, acknowledge with thanks DSR technical and financial support.

\section{References}

[1] JAGner D., Analyst, 107 (1275) (1982), 593.

[2] WANG J., Electroanal., 17 (2005), 1341.

[3] Zhou C.L., Lu Y., Li X.L., LuO C.N., Zhang Z., You J.M., Talanta, 46 (1998), 1531.

[4] Adeloju S.B., Young T.M., Anal. Chim. Acta, 302 (1994), 225.

[5] Brihaye C., Gillain G., Duyckaerts G., Anal. Chim. Acta, 148 (1983), 51.

[6] Woolever C., Starkey D.E., Dewald H.D., Forensic Sci. Int., 102 (1999), 45.

[7] Petrovic S.C., Dewald H.D., Anal. Chim. Acta, 357 (1997), 33.

[8] Illuminati S., Annibaldi A., Truzzi C., FiNALE C., SCARPoni G., Electrochim. Acta, 104 (2013), 148.

[9] Lust E., Jänes A., Lust K., Pullerits R., J. Electroanal. Chem., 431 (1997), 183.

[10] LV M., Wang X., Li J., Yang X., Zhang C., YANG J., Hu H., Electrochim. Acta, 108 (2013), 412.

[11] Mirceski V., Sebez B., JancovsKa M., Ogoreve B., Hocevar S.B., Electrochim. Acta, 105 (2013), 254.

[12] Renedo O.D., Martínez M.J.A., Anal. Chim. Acta, 589 (2007), 255.

[13] Salaün P., Gibbon-Walsh K., Berg C.M.G.V.D., Anal. Chem., 83 (2011), 3848.

[14] Zhu L., Xu L., Huang B., Jia N., Tan L., Yao S., Electrochim. Acta, 115 (2014), 471.

[15] Pan C., Li Y., Ma Y., ZhaO X., Zhang Q., J. Power Sources, 196 (2011), 6228.

[16] Czop E., Economou A., Bobrowski A., Electrochim. Acta, 56 (2011), 2206.

[17] Jovanovski V., HočEvar S.B., OgOrevc B., Electroanalysis, 21 (2009), 2321. 
[18] Tesarova E., Baldrianova L., Hocevar S.B., SVANCARA I., VyTRA K., OGOREVC B., Electrochim. Acta, 54 (2009), 1506.

[19] Toghill K.E., Xiao L., Wildgoose G.G., CompTON R.G., Electroanalysis, 21 (2009), 1113.

[20] Urbanová V., Vytřas K., KuHn A., Electrochem. Commun., 12 (2010), 114.

[21] Faroogi M.O., Taimoor A.A., Al-Shahrani S., BALEANU D., RATHER S.U., 4 (2015), 499.

[22] Kim K., Seo J., Nam J., IEEE T. Plasma Sci., 33 (2005), 813.

[23] Rosenblatt G.M., Birchenall C.E., J. Chem. Phys., 35 (2004), 788.

[24] Hamrin K., Johansson G., Gelius U., Nordling C. Siegbahn K., Phys. Scr., 1 (1970), 277.

[25] Clark D.T., Thomas H.R., J. Polym. Sci. Polym. Chem. Ed., 16 (1978), 791.

[26] Clark D.T., Kilcast D., Adams D.B., MusGRAVE W.K.R., J. Electron Spectros. Relat. Phenomena, (1975), 117.

[27] WAGNER C.D., Handbook of $x$-ray photoelectron spectroscopy: a reference book of standard data for use in $X$-ray photoelectron spectroscopy, Perkin-Elmer Corp., 1979.

[28] CRIST B.V., Handbook of monochromatic XPS spectra, Wiley, VCH, 2000.
[29] Morgab W.E., Stec W.J., WaZer J.R. V., Inorg. Chem., 12, (1972), 953.

[30] Beamson G., BRIgGs D., The scienta ESCA 300 database, in High Resolution XPS of Organic Polymers, Wiley, New York, 1992.

[31] BARD A.J. FAULKNER L.R., Electrochemical methods: fundamentals and applications, Wiley, New York, 1980.

[32] Svobodova-Tesarova E., Baldrianova L., StoCES M., Svancara I., Vytřas K., HoceVar S.B., OGOREvC B., Electrochim. Acta, 56 (2011), 6673.

[33] NuZhny A., J. Power Sources, 158 (2006), 920.

[34] Li Y., LiU X., Zeng X., LiU Y., LiU X., Wei W., LuO S., Sensor. Actuat. B-Chem., 139 (2009), 604.

[35] Ashrafi A.M., CerovaC S., Mudrić S., Guzsvány V., Husáková L., Urbanová I., Vytřas K., Sensor. Actuat. B-Chem., 191 (2014), 320.

[36] Ashrafi A.M., VytřAs K., Int. J. Electrochem. Sci., 7 (2012), 68.

[37] Wang Z., LiU G., Zhang L., WANG H., Int. J. Electrochem. Sci, 7 (2012), 12326.

[38] HočEvar S.B., ŠVANCARA I., Vytřas K., Ogoreve B., Electrochim. Acta, 51 (2005), 706.

[39] Jovanovski V., Hočevar S.B., Ogorevc B., Electroanal., 21 (2009), 2321

Received 2015-02-18 Accepted 2016-05-01 